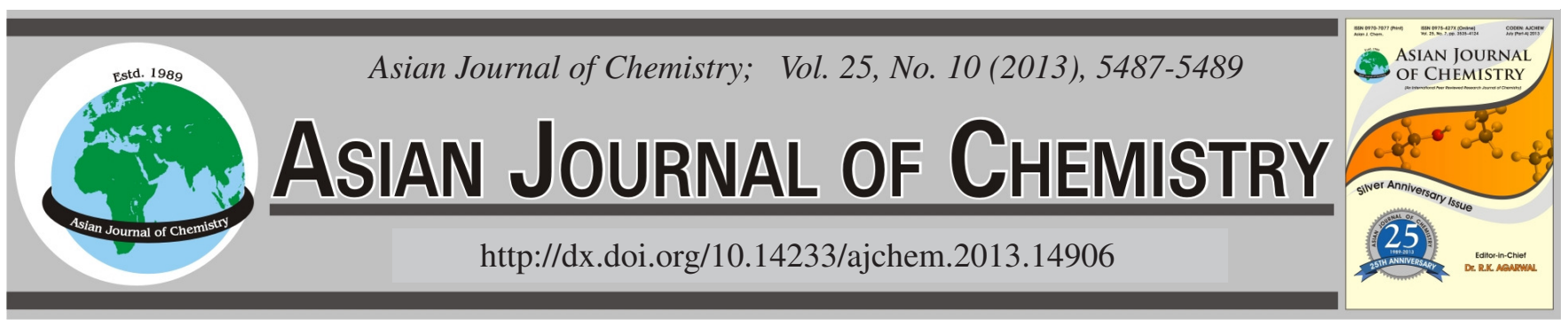

\title{
Synthesis of YAG Nano-powders and Transparent Ceramic by Microwave Homogeneous Precipitation
}

\author{
Fenghua JiAng ${ }^{1,2,}$, Degang ZhaO ${ }^{1}$ and JieqIANG $\mathrm{WANG}^{1}$
}

${ }^{1}$ School of Materials Science and Engineering, University of Jinan, Jinan 250022, P.R. China

${ }^{2}$ Shandong Provincial Key Laboratory of Preparation and Measurement of Building Materials, Jinan 250022, P.R. China

*Corresponding author: Tel: +86 531 88525387; E-mail: mse_jiangfh@ujn.edu.cn

(Received: 4 December 2012;

Accepted: 13 April 2013)

AJC-13237

\begin{abstract}
In this study, yttrium oxide, nitric acid, aluminum nitrate, urea and ammonium sulfate were used as raw materials to synthesize YAG nano powder by microwave homogeneous precipitation. The synthesized YAG nano-powders were analyzed and characterized by TG, XRD and SEM. Effects of initial concentration and calcination temperature on the average size of powder were studied. The results showed that the average diameter of YAG nano-powder is $84 \mathrm{~nm}$ under the optimized conditions. The green body of transparent ceramic, which is 13 $\mathrm{mm}$ in diameter and $3 \mathrm{~mm}$ in thickness, was calcined and prepared at $1500^{\circ} \mathrm{C}$ for $4 \mathrm{~h}$ under the unidirectional pressing. The microstructure of the green body was also studied.
\end{abstract}

Key Words: YAG nano-powders, Microwave homogeneous precipitation, Transparent ceramic.

\section{INTRODUCTION}

Transparent ceramics have a high strength, corrosion resistance, high temperature resistance, good insulation performance as well as transmission of light, can be manufactured into complex shapes and have a wide application prospect. Transparent ceramic first was prepared by Coble in 1957. In the past of decades, the researchers successfully developed dozens of transparent ceramics, such as $\mathrm{Al}_{2} \mathrm{O}_{3}, \mathrm{ZrO}_{2}$, $\mathrm{TiO}_{2}, \mathrm{AlN}, \mathrm{MgO}$ etc..$^{1-3}$.

Sekita et $a l .{ }^{4}$ prepared YAG transparent ceramics by homogeneous coprecipitation-vacuum sintering method using urea as precipitation agent. Ikesue et al..$^{5}$ prepared highly transparent YAG ceramics using high-purity yttria and alumina as raw material by isostatic pressing-solid state reaction method. Hreniak et $a l^{6}{ }^{6}$ reported the prepared Nd doped YAG transparent ceramics by low temperature and high pressure (LTHP) method. Rabinovitch et al. ${ }^{7}$ obtained YAG transparent ceramics with a relatively high density using freeze-drying method, which the powder was sintered at $1700{ }^{\circ} \mathrm{C}$ for $3 \mathrm{~h}$. Recently, Wenbin et al. ${ }^{8}$, prepared the YAG precursor powder using coprecipitation method and the transparent ceramic was sintered successfully. However, till now there are few reports about the synthesis of YAG powder using microwave homogeneous precipitation.

In this study, the YAG nano powder was synthesized by microwave homogeneous precipitation. The synthesized YAG nano-powders were analyzed and characterized by TG, XRD and SEM. The transparent ceramic was calcined successfully and the microstructure was analysized.

\section{EXPERIMENTAL}

Firstly, the yttrium nitrate solution was prepared. A certain amount of yttrium oxide dissolved in nitric acid and heated on a magnetic stirrer until the solution became colourless. A certain amount of aluminum nitrate was weighed and dissolved in water. The two solutions were mixed. Then the ammonium sulfate was selected as a dispersant, according to the molar ratio of 20:1 of urea and metal ion, in which the urea was precipitation agent. The concentrations of $\mathrm{Y}^{3+}$ and $\mathrm{Al}^{3+}$ in the solution were 0.09 and $0.15 \mathrm{~mol} / \mathrm{L}$, respectively. Then the solution was placed in the microwave furnace till no precipitation existed in the solution.

The solution was centrifuged and washed until there was no turbidity in the supernatant. After centrifugation, the precipitate was placed in a vacuum oven and dried. The dried precipitate was removed by grinding for differential thermal analysis. According to the results of DTA, the calcining temperature of nano-powder was determined.

The body with the diameter of $13 \mathrm{~mm}$ and the thickness of $3 \mathrm{~mm}$ was pressed using YAG nano- powder by a conventional steel mold. Then the body was calcinated in vacuum at $1500{ }^{\circ} \mathrm{C}$ for $4 \mathrm{~h}$. The constituent phase of nano-powder was determined by X-ray diffractometry $\left(\mathrm{CuK}_{\alpha}\right.$, Rigaku, Rint2000). The microstructure of nano- powder was observed by SEM and the compositions transparent ceramic was determined by energy dispersive spectrometer. 


\section{RESULTS AND DISCUSSION}

XRD analysis: Fig. 1 shows the XRD pattern of synthesized YAG nano- powder after calcination. It can be seen that there is no other peaks other than YAG phase, which is agreeable with the standard diffraction chart of YAG is 01-082-0573 indicating the YAG phase has good crystallinity and there is no impurities.

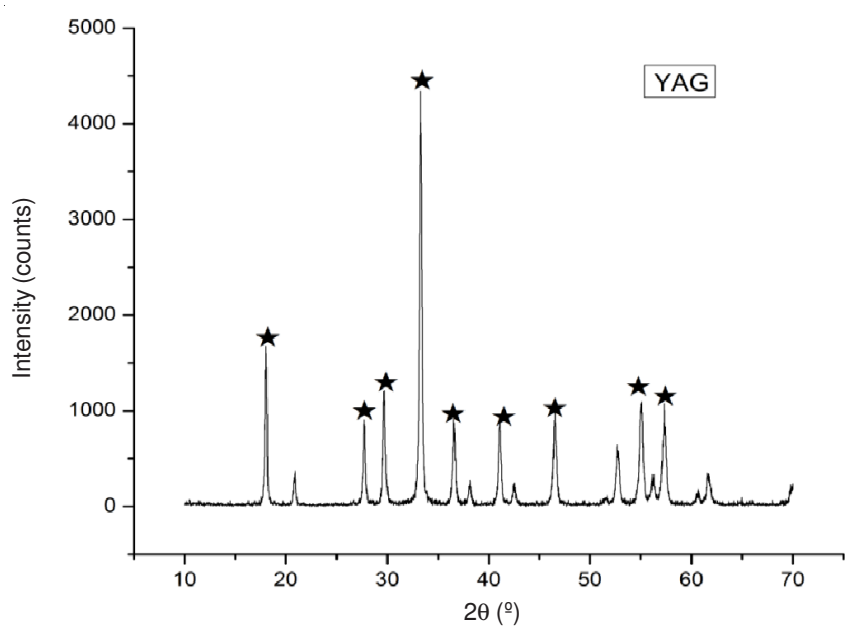

Fig. 1. XRD pattern of synthesized YAG nano- powder after calcination

DTA and TG analysis: Fig. 2 is the DTA and TG results of synthesized YAG nano- powder in the range of room temperature to $1200{ }^{\circ} \mathrm{C}$. It can be seen from the TG curve that the curve continuous declined from room temperature to $1200{ }^{\circ} \mathrm{C}$, suggesting that the loss of sample was a continuous process. The weight loss reached over $90 \%$ before $450{ }^{\circ} \mathrm{C}$, indicating the YAG nano- powder mainly converted to oxides at $450{ }^{\circ} \mathrm{C}$ precipitate and the mass loss was mainly caused by the decomposition of the evaporation of the adsorbed water in the $\mathrm{Al}(\mathrm{OH})_{3}$ and $\mathrm{Y}(\mathrm{OH})_{3}$. In the DTA curve, there were two endothermic peaks and an exothermic peak. The exothermic peak appeared at about $100{ }^{\circ} \mathrm{C}$ was due to the loss of adsorbed water and crystallization water in the precursor. The endothermic peak of $850{ }^{\circ} \mathrm{C}$ was attributed to the crystalline of $\mathrm{Y}_{4} \mathrm{Al}_{2} \mathrm{O}_{9}$ (YAM) phase. The endothermic peak of $950^{\circ} \mathrm{C}$ illustrated the YAG phase began to form.

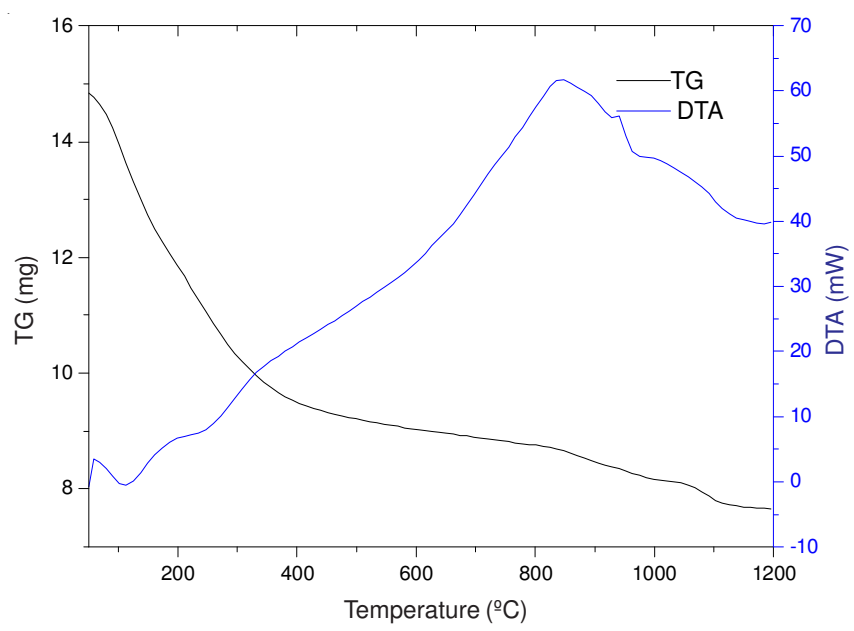

Fig. 2. DTA curve and TG curve of synthesized YAG nano-powder
Grading analysis and microstructure of YAG nano powder: Fig. 3 shows the grading analysis result of synthesized YAG nano-powder. It can be seen that the particle size of the YAG samples agreed with normal distribution. The minimum particle diameter was less than $40 \mathrm{~nm}$ and the average particle diameter was about $130 \mathrm{~nm}$. Table-1 lists the size distribution of YAG nano-powder. It can be seen that the particles less 53 $\mathrm{nm}, 61 \mathrm{~nm}$ and $73 \mathrm{~nm}$ were nearly $10 \%, 25 \%, 50 \%$ in the YAG nano- powder, respectively. The particle less $96 \mathrm{~nm}$ was nearly $75 \%$, indicating the size distribution of particle was well and the synthesized powder was nano size.

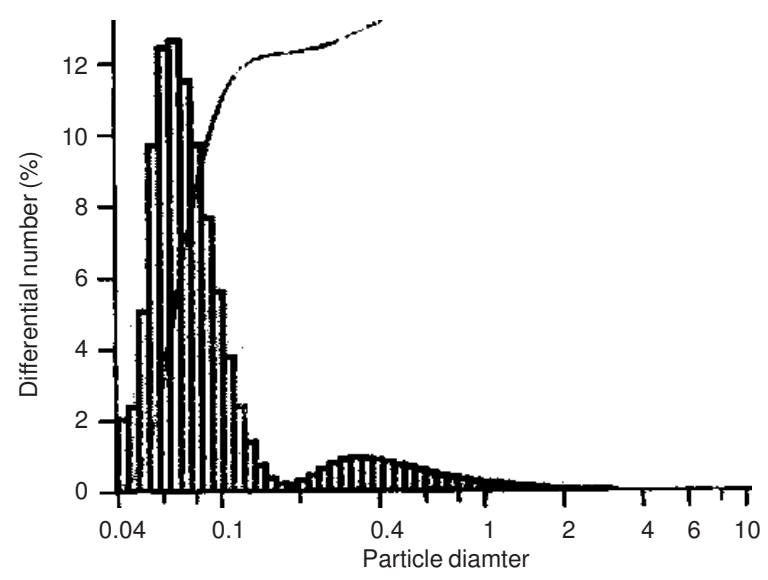

Fig. 3. Grading analysis result of synthesized YAG nano- powder

\begin{tabular}{ccccc} 
TABLE-1 \\
GRADING ANALYSIS TABLE OF SYNTHESIZED \\
YAG NANO- POWDER \\
\hline$<10 \%$ & $<25 \%$ & $<50 \%$ & $<75 \%$ & $<90 \%$ \\
\hline $0.053 \mu \mathrm{m}$ & $0.061 \mu \mathrm{m}$ & $0.073 \mu \mathrm{m}$ & $0.096 \mu \mathrm{m}$ & $0.277 \mu \mathrm{m}$ \\
\hline
\end{tabular}

Fig. 4 shows the microstructure of synthesized YAG nanopowder. It can be seen that the most of the particles of calcined YAG powder was relatively small and distributed well. The morphology of particle was regular and nearly spherical. Only a small part of particles agglomerated, just as shown in Fig. 4. The average diameter of particle was about $70 \mathrm{~nm}$, which was consistent with the particle size analysis in Fig. 3.

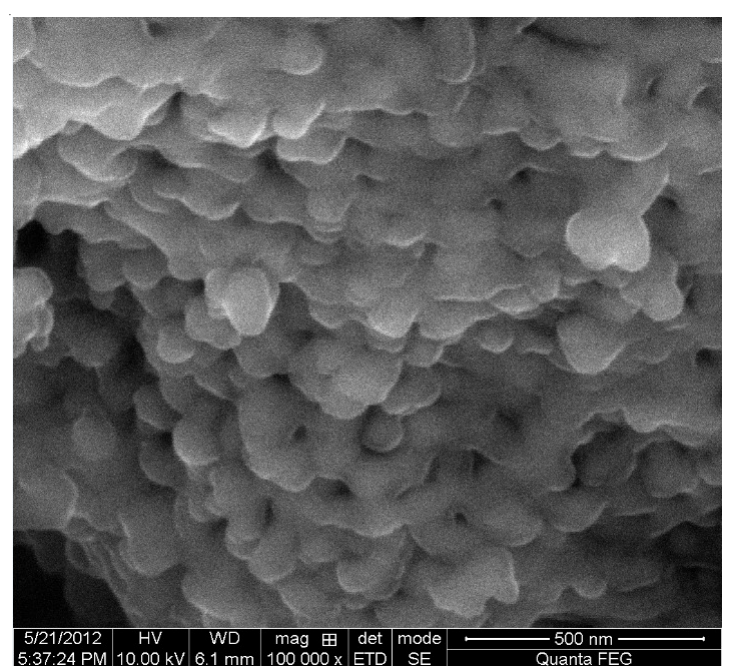

Fig. 4. Microstructure of synthesized YAG nano- powder (a) 50000×; (b) $100000 x$ 
Microstructure of YAG transparent ceramic: Fig. 5 shows the microstructure of calcined green body of YAG transparent ceramic. It can be observed that the particles were spherical and the average size of particle was about $200 \mathrm{~nm}$. The YAG transparent ceramic was relatively density. Some voids still existed in some area, just as shown in Fig. 5.
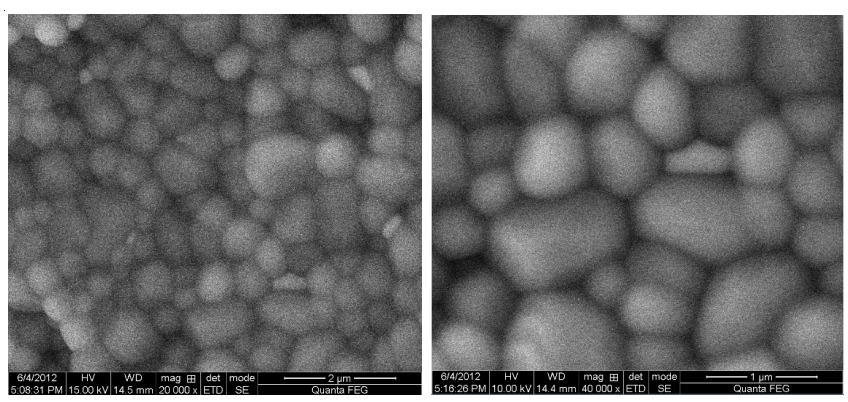

Fig. 5. Microstructure of calcined green body of YAG transparent ceramic (a) $20000 x$; (b) $40000 x$

\section{Conclusion}

YAG nano- powder was synthesized by microwave homogeneous precipitation. The minimum size of particle was less than $40 \mathrm{~nm}$ and the average diameter of particle of was about
$130 \mathrm{~nm}$. The median diameter of spherical particles was approximately $73 \mathrm{~nm}$.

The green body of transparent ceramic, which is $13 \mathrm{~mm}$ in diameter and $3 \mathrm{~mm}$ in thickness, was calcined and prepared at $1500{ }^{\circ} \mathrm{C}$ for $4 \mathrm{~h}$ under the unidirectional pressing.

\section{ACKNOWLEDGEMENTS}

Financial support from Doctoral Fund of University of Jinan is acknowledged.

\section{REFERENCES}

1. G. Dewith and H.J. Vandijk, Mater. Res. Bull., 19, 1669 (1984).

2. Y. Yoshikawa, T. Hanada and T. Kogai, J. Eur. Ceram. Soc., 24, 1041 (2004).

3. J. Trojan, E. Zych, D. Hreniak and W. Strek, J. Alloys Compd., 380, 123 (2004).

4. M. Sekita, H. Haneda and T. Yanagitani, J. Appl. Phys., 67, 453 (1990).

5. A. Ikesue, I. Furusato and K. Kamata, J. Eur. Ceram. Soc., 5, 53 (1995).

6. E. Zych, D. Hreniak, W. Strek, L. Kepinski and K. Domagala, J. Alloys Compd., 341, 391 (2002).

7. Y. Rabinovitch, D. Tetard and M.D. Faucher, Opt. Mater, 24, 345 (2003).

8. H.M. Kou, Y.B. Pan, K. Tomoaki, J. Li and J.K. Guo, J. Inorg. Mater, 23, 1037 (2008). 